\title{
HIV and HPV infections and ocular surface squamous neoplasia: systematic review and meta-analysis
}

H Carreira ${ }^{*, 1,2}$, F Coutinho ${ }^{1,3}$, C Carrilho ${ }^{4,5}$ and N Lunet ${ }^{1,2}$

${ }^{1}$ Institute of Public Health of the University of Porto, Porto, Portugal; ${ }^{2}$ Department of Clinical Epidemiology, Predictive Medicine and Public Health of the University of Porto Medical School, Porto, Portugal; ${ }^{3}$ Department of Oncology, Centro Hospitalar do Porto, Porto, Portugal; ${ }^{4}$ Department of Pathology, Medical Faculty, Eduardo Mondlane University, Maputo, Mozambique and ${ }^{5}$ Department of Anatomical Pathology, Maputo Central Hospital, Maputo, Mozambique

Background: The frequency of ocular surface squamous neoplasias (OSSNs) has been increasing in populations with a high prevalence of infection with human immunodeficiency virus/acquired immunodeficiency syndrome (HIV/AIDS) and infection with human papillomavirus (HPV). We aimed to quantify the association between HIV/AIDS and HPV infection and OSSN, through systematic review and meta-analysis.

Methods: The articles providing data on the association between HIV/AIDS and/or HPV infection and OSSN were identified in MEDLINE, SCOPUS and EMBASE searched up to May 2013, and through backward citation tracking. The DerSimonian and Laird method was used to compute summary relative risk (RR) estimates and $95 \%$ confidence intervals $(95 \% \mathrm{Cl})$. Heterogeneity was quantified with the $P^{2}$ statistic.

Results: HIV/AIDS was strongly associated with an increased risk of OSSN (summary RR=8.06, 95\% Cl: 5.29-12.30, $P^{2}=56.0 \%, 12$ studies). The summary RR estimate for the infection with mucosal HPV subtypes was 3.13 (95\% Cl: $1.72-5.71, I^{2}=45.6 \%, 16$ studies). Four studies addressed the association between both cutaneous and mucosal HPV subtypes and OSSN; the summary RR estimates were 3.52 (95\% Cl: $\left.1.23-10.08, P^{2}=21.8 \%\right)$ and 1.08 (95\% Cl: $\left.0.57-2.05, l^{2}=0.0 \%\right)$, respectively.

Conclusion: Human immunodeficiency virus infection increases the risk of OSSN by nearly eight-fold. Regarding HPV infection, only the cutaneous subtypes seem to be a risk factor.

The term ocular surface squamous neoplasia (OSSN) comprises a wide variety of lesions of the conjunctiva and cornea, ranging from mild dysplasia to carcinoma in situ and, in a later stage, invasive squamous cell carcinoma (SCC; Nagaiah et al, 2010; Di Girolamo, 2012).

Although OSSN are rare conditions, they are among the most frequent ocular surface tumours (Grossniklaus et al, 1987), and an increase in their frequency has been reported since the 1980s (Chokunonga et al, 1999; Parkin et al, 1999; Wabinga et al, 2000), especially in sub-Saharan Africa. This paralleled the spread of the human immunodeficiency virus/acquired immunodeficiency syndrome (HIV/AIDS) epidemic in this setting. Chronic immunosuppression is currently a well-accepted risk factor for OSSN (Shields et al, 2011), although to our knowledge there are no quantitative syntheses of the results linking HIV/AIDS with OSSN based on a systematic review of the literature.

Risk factors other than HIV include fair skin, ocular pigmentation, smoking and exposure to solar ultraviolet radiation (Kiire and Dhillon, 2006). Human papillomavirus (HPV) has been identified in tumour specimens from several case series (Saegusa et al, 1995; Moubayed et al, 2004; Ateenyi-Agaba et al, 2010; Chauhan et al, 2012) and an association between HPV infection and OSSN has 
also been suggested (Scott et al, 2002; Ateenyi-Agaba et al, 2004). However, the specific contribution of the different mucosal and cutaneous HPV subtypes has seldom been addressed in the same study, as shown in a previous systematic review by de Koning et al (2008), although no meta-analysis was conducted.

Therefore, we updated previous systematic reviews and/or metaanalyses that addressed the association between HIV/AIDS and HPV (cutaneous and mucosal subtypes) infections and OSSN.

\section{MATERIALS AND METHODS}

Search strategy. We searched MEDLINE (through PubMed), EMBASE (through OVID) and SCOPUS, from inception to May 2013, to identify studies addressing the association between infection with HIV and/or HPV and OSSN; the search expressions are provided in the systematic review flowchart (Figure 1, Supplementary Information). We also screened the lists of bibliographic references of the original reports considered eligible for the systematic review and review articles on these topics.

Selection of the studies. We aimed to select cohort, case-control or cross-sectional analyses addressing the association between infection with HIV and/or mucosal or cutaneous HPV and OSSN. Studies should provide enough detail to characterise the population, the methods involved to evaluate HIV and/or HPV infection status and the outcomes under study.

The eligibility of the studies was independently assessed by two researchers (HC and FC), in three consecutive steps, applying predefined criteria. In the first step, the studies were excluded considering only the information presented in the title and abstract; when the abstract of a particular article was not available, it was considered for further evaluation. In the second step, the full texts of the articles not previously excluded were assessed to determine their eligibility for the review, using the same set of criteria. In the third step, the full texts were re-evaluated to determine the eligibility for meta-analyses.

The exclusion criteria were the following: (1) reports not evaluating human subjects (e.g. in vitro studies); (2) review articles, guidelines, comments or conference abstracts; (3) OSSN case reports or case series; (4) studies not providing a relative risk (RR) estimate for the association between HIV and/or HPV infection and OSSN, or the necessary information to compute it; (5) multiple reports of the same data; (6) not providing enough information to characterise the control population. There were no language restrictions.

Among reports with overlapping samples, we selected those providing data regarding the largest number of cases, with RR estimates adjusted for the largest number of potential confounders or presenting more detailed information regarding the sample characteristics, by applying these criteria consecutively.

We excluded one study (McDonnell et al, 1986), conducted in the United Sates because the methods used did not allow to characterise the HPV subtypes involved. We further excluded four studies more likely to have yielded biased estimates of the association between HIV infection and OSSN because (1) controls were recruited among subjects undergoing screening for HIV infection (Waddell et al, 2010); (2) a standardised incidence ratio was computed using the observed number of SCC of the conjunctiva (SCCC) and the estimated number of all cases of eye cancer (Mbulaiteye et al, 2006); (3) the outcome was ocular cancer, excluding only retinoblastoma and neuroblastoma (Newton et al, 1995);

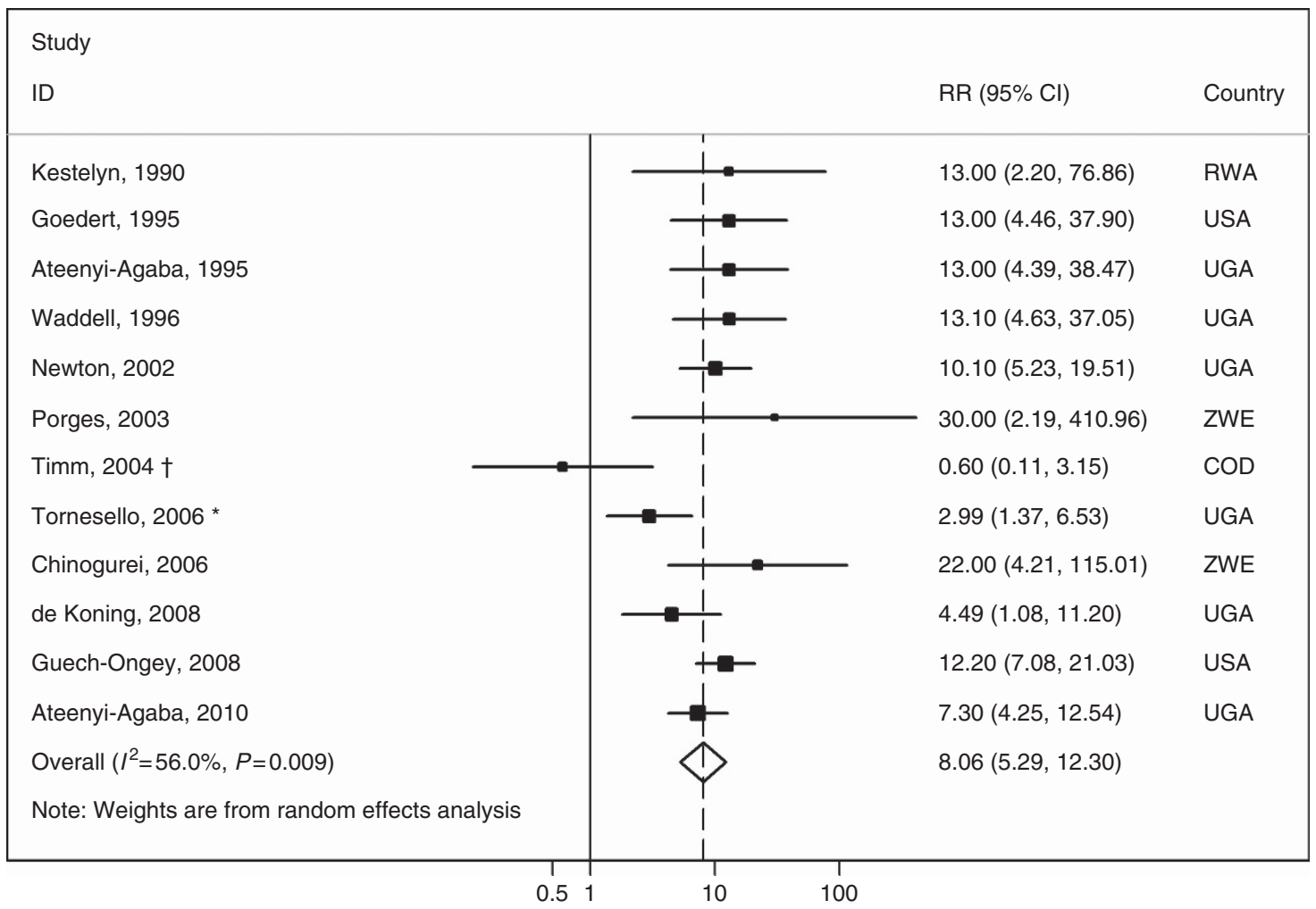

Figure 1. Meta-analysis of the studies assessing the relation between HIV infection and OSSN. * indicates that this RR estimate was computed by the authors of the present meta-analysis with data provided in the original report although the controls were frequency age- and sex-matched with the cases; a sensitivity analysis excluding this study yielded a summary RR of 9.1 ( $\left.95 \% \mathrm{Cl}: 6.1-13.6, I^{2}=43.8 \%\right)$. $\dagger$ indicates that when this study was excluded, the summary RR estimate was 8.9 (95\% Cl: 6.3-12.5, $\left.I^{2}=34.2 \%\right)$. Abbreviations: COD = Congo, Democratic Republic; RR= relative risk; $\mathrm{RWA}=$ Rwanda; UGA = Uganda; USA = United States of America; ZWE = Zimbabwe. 
(4) the control group only included AIDS-defining malignancies (Ebughe et al, 2012); (5) compared the prevalence of HIV among the SCCC cases with the prevalence of HIV of the general population (Spitzer et al, 2009).

The decisions taken independently by the reviewers in each step were compared and the discrepancies were resolved by consensus or involving a third researcher (NL or CC).

Data extraction and meta-analysis. Data extraction was performed independently by two researchers (HC and FC); nonconcordant outputs were discussed until consensus or involving a third researcher (NL or CC).

A predefined form was used to collect information on the following items: (1) year of publication; (2) country and region where the sample was assembled; (3) characteristics of the cases and controls (sample size, age distribution, procedures for recruitment of the participants); (4) diagnostic methods used to assess the HIV and HPV infection statuses; (5) subtypes of HIV and HPV detected, whenever available; (6) RR estimates and corresponding precision estimates, or the necessary information to compute them, preferably adjusted for the largest number of possible confounders, for the association between HIV/AIDS or different HPV subtypes, namely cutaneous and mucosal (de Villiers et al, 2004), and OSSN; (7) RR estimates for the association between HPV infection and OSSN, by HIV infection status, whenever available. For the studies including no infected cases among one group of subjects, we estimated the odds ratio (OR) and respective 95\% confidence intervals $(95 \% \mathrm{CI})$ using the metan command of STATA (Stata Corp., College Station, TX, USA), which adds by default 0.5 to all cells of the $2 \times 2$ table of the study (Harris et al, 2008).

We conducted meta-analyses for the association between HIV, cutaneous HPV and mucosal HPV infections and OSSN. The DerSimonian and Laird method was used to compute summary RR estimates with 95\% CI. Heterogeneity was quantified using the $I^{2}$ statistic (Higgins and Thompson, 2002).

As pterygium and pingueculae have been suggested to be associated with HPV infection (Reid and Dushku, 2003; Di Girolamo, 2012), we conducted sensitivity analyses excluding the studies with $>10 \%$ of subjects with these conditions in the control group (McDonnell et al, 1989; Tabrizi et al, 1997; Dushku et al, 1999; Ateenyi-Agaba et al, 2004; Simbiri et al, 2010; Carrilho et al, 2013).

Publication bias was assessed through visual inspection of funnel plots and Egger's regression asymmetry test (Sterne et al, 2000).

The statistical analysis was performed using STATA, version 9.2 (Stata Corp.).

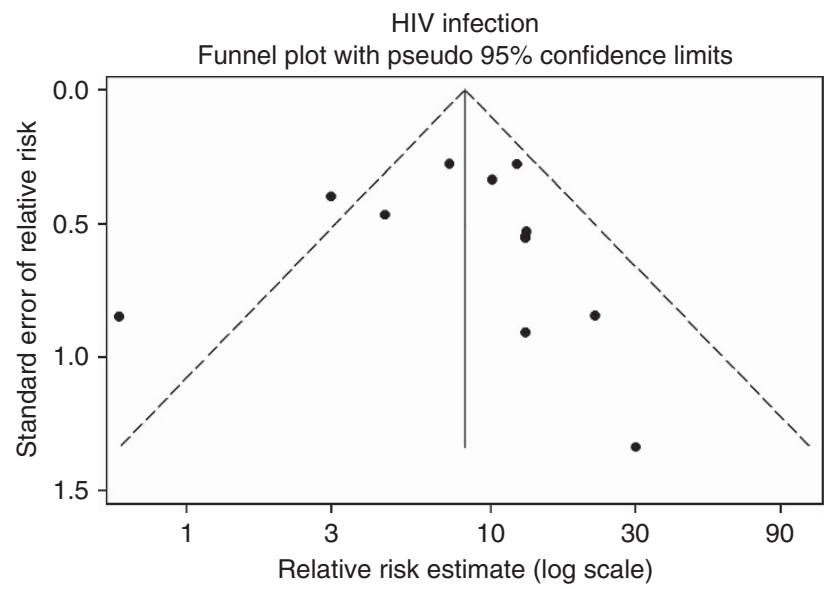

\section{RESULTS}

HIV infection and OSSN. Twelve studies provided data to assess the relation between HIV infection and OSSN (Kestelyn et al, 1990; Ateenyi-Agaba, 1995; Goedert and Cote, 1995; Waddell et al, 1996; Newton et al, 2002; Porges and Groisman, 2003; Timm et al, 2004; Chinogurei et al, 2006; Tornesello et al, 2006; de Koning et al, 2008; Guech-Ongey et al, 2008; Ateenyi-Agaba et al, 2010), of which 10 were conducted in Africa, mostly in Uganda, and two in the United States. The subtype of HIV involved was seldom available (Newton et al, 2002). With the exception of the two studies conducted in the United States (Goedert and Cote, 1995; Guech-Ongey et al, 2008), all were case-control analyses. Only three studies provided RR estimates adjusted for potential confounders (Newton et al, 2002; Guech-Ongey et al, 2008; Ateenyi-Agaba et al, 2010), mostly age and sex.

Human immunodeficiency virus infection strongly increased the risk of OSSN; the overall RR estimate was 8.06 (95\% CI: 5.29$12.30, I^{2}=56.0 \%$; Figure 1). The visual inspection of the funnel plot suggests the existence of publication bias, with smaller studies with weaker associations being underrepresented (Figure 2), although it is not statistically significant according to Egger's regression asymmetry test $(P=0.596)$.

In the study by Ateenyi-Agaba et al (2010), the OR was 5.6 (95\% CI: 1.5-20.3) for the comparison of AIDS patients with those infected with HIV but without an AIDS diagnosis. The two investigations conducted in the United States (Goedert and Cote, 1995; Guech-Ongey et al, 2008) showed that the risk of OSSN among the HIV-infected varied with the time in relation to the diagnosis of AIDS. In the study by Goedert and Cote (1995), 2 years after the diagnosis the ratio between observed and expected SCCC cases was 196 (95\% CI: 24-708), and Guech-Ongey et al (2008) observed a stronger association in the period of -6 to +3 months relative to the AIDS onset.

People with AIDS were overrepresented in the cohorts of HIVinfected subjects evaluated in the two studies from the United States (Goedert and Cote, 1995; Guech-Ongey et al, 2008). Their exclusion from the meta-analysis resulted in a summary RR of 7.17 (95\% CI: $4.32-11.90, I^{2}=57.6 \%$ ).

HPV infection and OSSN. Twenty two studies provided data to assess the association between infection with mucosal and/or cutaneous HPV subtypes and OSSN (Supplementary Information).

Five studies (Ateenyi-Agaba et al, 2004; Tornesello et al, 2006; de Koning et al, 2008; Ateenyi-Agaba et al, 2010; Carrilho et al, 2013),

Figure 2. Funnel plots of studies evaluating the association between human immunodeficiency virus (HIV) and mucosal human papillomavirus (HPV) infection and OSSN. 
four conducted in Uganda and one in Mozambique, addressed the association between infection with cutaneous subtypes of HPV and OSSN. The summary RR was 3.82 (95\% CI: 1.77-8.22, $I^{2}=13.0 \%$; Figure 3 ), similar among HIV-infected and non-infected subjects (Figure 4). Excluding two studies (Ateenyi-Agaba et al, 2004; Carrilho et al, 2013) in which pterygia or pinguecula patients represented $>10 \%$ of the controls, the summary RR was 3.52 (95\% CI: 1.23-10.08, $\left.I^{2}=21.8 \%\right)$.

Sixteen studies, conducted in 10 countries, provided data to assess the association between mucosal HPV infection, mostly with subtypes 16 and 18, and OSSN (McDonnell et al, 1989; Adachi et al, 1995; Saegusa et al, 1995; Waddell et al, 1996; Karcioglu and Issa, 1997; Tabrizi et al, 1997; Palazzi et al, 2000; Newton et al,
2002; Scott et al, 2002; Tornesello et al, 2006; Auw-Haedrich et al, 2008; de Koning et al, 2008; Ateenyi-Agaba et al, 2010; AsadiAmoli et al, 2011; Chauhan et al, 2012; Carrilho et al, 2013); the summary RR was 3.13 (95\% CI: $1.72-5.71, I^{2}=45.6 \%$; Figure 3). When excluding the three studies having $>10 \%$ of controls with pterygia or pinguecula (McDonnell et al, 1989; Tabrizi et al, 1997; Carrilho et al, 2013), the summary RR estimate was 2.50 (95\% CI: $\left.1.35-4.65, I^{2}=37.4 \%\right)$.

Four studies, conducted in Germany (Guthoff et al, 2009), India (Sen et al, 2007), Thailand (Tulvatana et al, 2003) and the United States (Dushku et al, 1999) did not find any mucosal HPV-positive specimen, neither among cases nor among controls, and therefore could not be considered for meta-analysis (Supplementary Information).

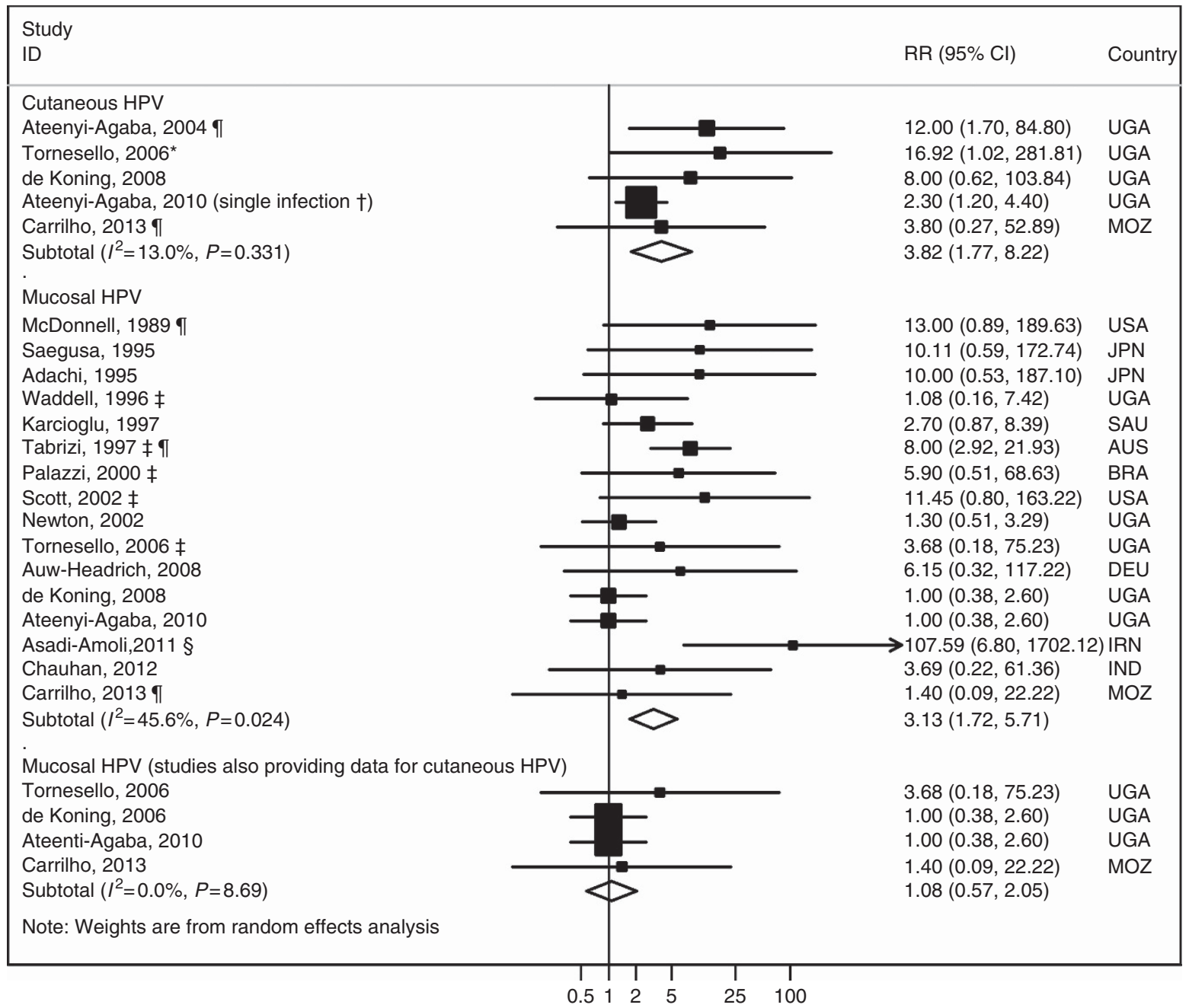

Figure 3. Meta-analyses of the studies assessing the relation between infection with cutaneous and mucosal human papillomavirus (HPV) subtypes and OSSN. * indicates that this RR estimate was computed by the authors of the present meta-analysis with data provided in the original report, although the controls were frequency age- and sex-matched with the cases; a sensitivity analysis excluding this study yielded virtually the same results $\left(R R=3.10,95 \% \mathrm{Cl}: 1.59-6.03, P^{2}=5.0 \%\right)$. $\dagger$ indicates that from this study RR estimates were available both for multiple and single infection, and the latter was selected for meta-analysis because it was more common than multiple infections (among the HPV-infected, 54.5\% were infected with a single type and the remaining with multiple); in a sensitivity analysis including the estimate for multiple infection (OR=18.3, 95\% Cl: 6.2-54.4), the overall RR estimate was 13.44 (95\% Cl: 5.99-30.15, $P^{2}=0.0 \%$ ). $\ddagger$ indicates that the RR estimates were computed by the authors of the present meta-analysis with data provided in the original report, although these five studies were matched case-control studies; the overall RR estimate is $2.58(95 \% \mathrm{Cl}: 1.28-5.16$, $\left.P^{2}=44.7 \%\right)$ if these studies are excluded. $\S$ indicates that excluding this study, the summary RR estimate was 2.55 (95\% $\left.\mathrm{Cl}: 1.51-4.29, P=30.5 \%\right)$. indicates these studies include $>10 \%$ of the subjects in the control group with pterygia or pinguecula. When excluding them from the analysis, the overall RR estimate was 3.52 (95\% Cl: 1.23-10.08, $\left.\mathrm{l}^{2}=21.8 \%\right)$ and 2.50 (95\% Cl: 1.35-4.65) for the association between cutaneous and mucosal HPV and OSSN, respectively. Abbreviations: AUS = Australia; BRA = Brazil; $D E U=$ Germany; IND = India; IRN = Iran; JPN = Japan; MOZ=Mozambique; RR= relative risk; $\mathrm{SAU}=$ Saudi Arabia; UGA = Uganda; USA $=$ United States of America. 


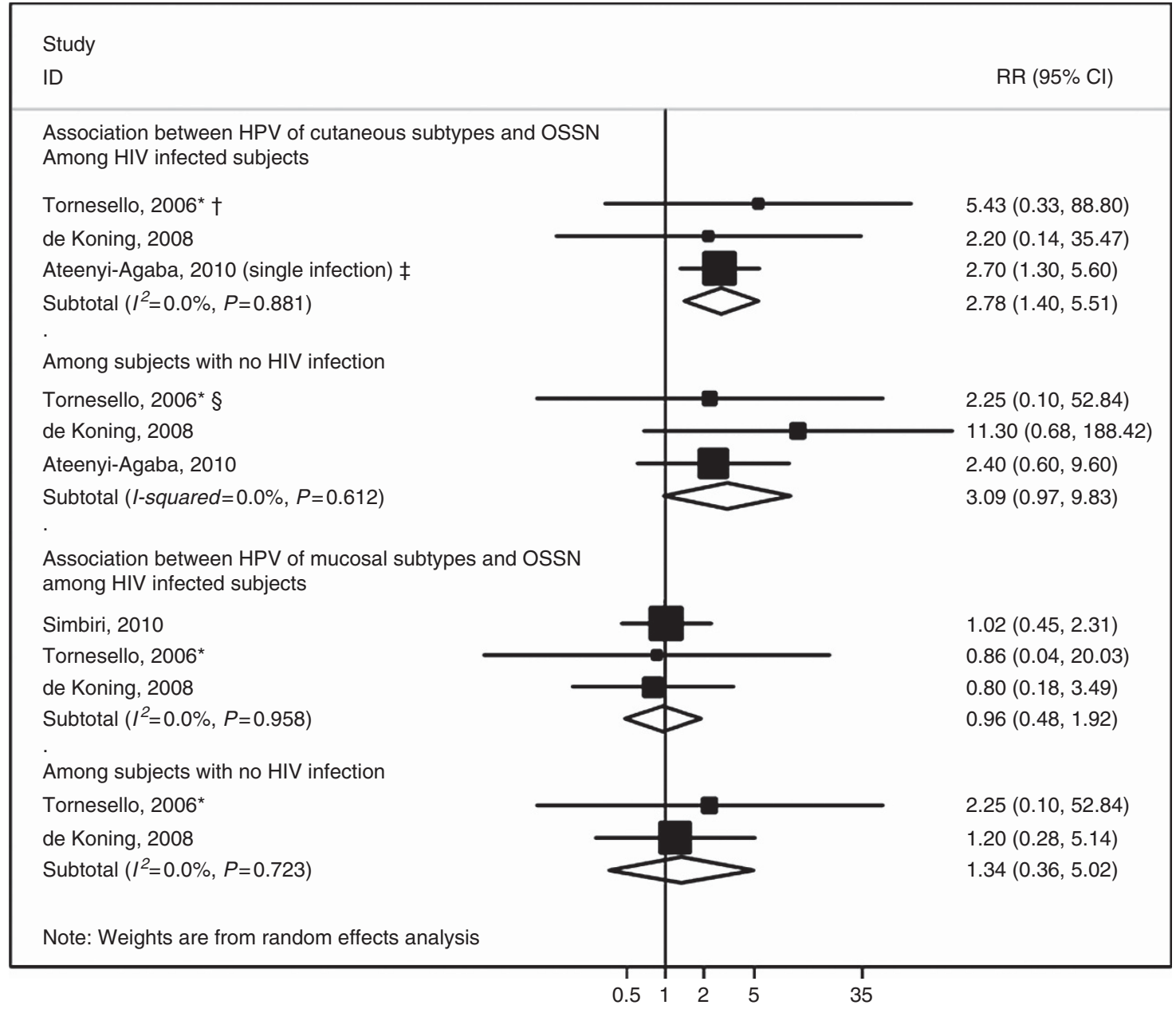

Figure 4. Meta-analyses of the studies addressing the association between human papillomavirus (HPV) infection and ocular surface squamous neoplasia (OSSN) by HIV status. * indicates that this RR estimate was computed by the authors of the present meta-analysis with data provided in the original report, although the controls were frequency age- and sex-matched with the cases; $\dagger$ indicates that a sensitivity analysis excluding this study yielded an overall RR of 2.66 ( $95 \% \mathrm{Cl}$ : 1.33-5.40, $I^{2}=0.0 \%$ ); $\ddagger$ indicates that from this study RR estimates are available both for multiple and single infection, and the latter was selected for meta-analysis because it was more common than multiple infections (among the HPV-infected, $54.5 \%$ were infected with a single type and the remaining with multiple); in a sensitivity analysis including the estimate for multiple infection $(\mathrm{OR}=15.4,95 \% \mathrm{Cl}: 5.2-45.4)$, the overall relative $\mathrm{RR}$ estimate was $11.87\left(95 \% \mathrm{Cl}: 5.13-27.46, \mathrm{I}^{2}=6.9 \%\right)$; $\S$ indicates that a sensitivity analysis excluding this study yielded an overall RR of 3.25 (95\% Cl: $\left.0.94-11.27, l^{2}=0.0 \%\right)$. Abbreviation: RR= relative risk.

The visual inspection of the funnel plot suggests publication bias, as small studies yielding negative associations between infection with mucosal HPV subtypes and OSSN are underrepresented (Figure 2). This is supported by the results of Egger's regression asymmetry test $(P=0.023)$.

When considering only the results of the four studies (Tornesello et al, 2006; de Koning et al, 2008; Ateenyi-Agaba et al, 2010; Carrilho et al, 2013) providing data also for cutaneous subtypes of HPV, the summary RR was 1.08 (95\% CI: $0.57-2.05, I^{2}=0.0 \%$; Figure 3 ).

The association between mucosal subtypes of HPV and the OSSN was similar according to the participants' HIV infection status, although this information could be obtained only from a subsample of the studies (Figure 4).

\section{DISCUSSION}

This study confirms that HIV infection strongly increases the risk of OSSN. Although the evidence regarding the role of HPV infection is less conclusive, the results from studies that evaluated both cutaneous and mucosal subtypes of HPV suggest that only the cutaneous HPV subtypes are associated with an increased risk of OSSN.
We conducted a comprehensive systematic review, using three of the most important biomedical databases and backward citation tracking of review articles and eligible reports. A large number of potential relevant bibliographic references were screened, not only from MEDLINE-indexed publications but also from journals with smaller impact. Nevertheless, the summary RR may be overestimated because of publication bias, although not compromising the validity of our conclusion of a positive and strong association between HIV infection and OSSN. Immunossupression has a central role in this relation (Holkar et al, 2005; Grulich et al, 2007), and its later stage in patients with AIDS is probably reflected in a stronger association with OSSN. Unfortunately, the data addressing this specific aspect was scarce, and a quantitative synthesis of the results on the association between AIDS and OSSN could not be accomplished. Differences between studies regarding its design and the proportion of people with AIDS and on highly active antiretroviral therapy could have contributed to the observed heterogeneity of results, although the $I^{2}$ statistic decreased just slightly when the cohort studies conducted in the United States were excluded in a sensitivity analysis.

Regarding the relation between HPV and OSSN, only five studies provided data to assess the specific effect of cutaneous 
subtypes, and this small number precludes a formal assessment of the publication bias. Although we cannot rule out publication bias, the inclusion of the estimate for single infection from the study of Ateenyi-Agaba et al (2010) resulted in a conservative estimate of the association between infection with cutaneous subtypes of HPV and OSSN. In a sensitivity analysis including both estimates for single and multiple infection, the summary RR estimate was 7.19, $95 \%$ CI: $2.52-20.50, I^{2}=60.1 \%$ ), and the publication bias appears less likely. On the other hand, it is clear that smaller studies yielded stronger estimates of the association between HPV infection with mucosal subtypes and OSSN. However, the four reports (Dushku et al, 1999; Tulvatana et al, 2003; Sen et al, 2007; Guthoff et al, 2009) that did not detect HPV of mucosal subtypes neither in cases nor in controls are not represented in the funnel plot, which is in accordance with other case series that did not detect HPV of mucosal subtypes in SCCC specimens (Eng et al, 2002; Manderwad et al, 2009). Although the lack of sensitivity of the methods used to assess infection status may contribute to spuriously low prevalences of HPV, these results argue against a strong role of the mucosal subtypes of HPV in the aetiology of OSSN.

Considering that the association between HPV infection with mucosal subtypes was weaker than that for cutaneous HPV, especially when accounting for the results from the studies that addressed the role of infection with both subtypes, our metaanalysis adds to previous research (IARC Working Group on the Evaluation of Carcinogenic Risks to Humans, 2012) evidence of a stronger role of cutaneous HPV infection in the aetiology of OSSN.

Previous studies have reviewed the role of HIV and HPV infections and the risk of SCCC (Newton, 1996; Sasco et al, 2010). Regarding the former, Newton (1996) in 1996 combined the RR estimates of four studies and provided a summary RR of 13.0 (95\% CI: 7.2-23.1). In addition, Sasco et al (2010) systematically reviewed the available information on this topic, but they did not perform a meta-analysis. Recently the evidence on this topic was considered to be sufficient to establish HIV as an oncogenic factor for conjunctival cancer (Bouvard et al, 2009). Our study adds eight additional studies to the previous quantitative synthesis, along with a formal assessment of the potential selection bias underlying the summary estimate.

In 1996, Newton (1996) also described the proportion of controls and SCCC cases infected with HPV in case series and case-control studies. Our systematic review identified 18 more studies for which it was possible to compare the frequency of HPV infection among cases and a comparison group. More recently, de Koning et al (2008) presented, together with their case-control study, a systematic review of the literature on the association between HPV infection and SCCC, including studies published up to 2008. The present systematic review included six additional studies (Auw-Haedrich et al, 2008; Guthoff et al, 2009; AteenyiAgaba et al, 2010; Asadi-Amoli et al, 2011; Chauhan et al, 2012; Carrilho et al, 2013) published since then, although only one provided information that could be used to assess the association between infection with cutaneous subtypes of HPV and SCCC. Our study also adds to the previous reports the assessment of a potential interaction between HIV and HPV infections, although further research is needed for more robust conclusions on this issue, and the demonstration that the published evidence on the association between mucosal HPV and SCCC overestimates the true association.

The conclusions of our review are naturally limited by the methodological quality of the original studies. Although some investigations involved consecutive patients attending some healthcare facility (Kestelyn et al, 1990; Ateenyi-Agaba, 1995; Newton et al, 2002; Scott et al, 2002; de Koning et al, 2008; Ateenyi-Agaba et al, 2010; Waddell et al, 2010), others provided relatively poor descriptions of the patients studied, precluding a systematic assessment of potential biases. It was not possible to characterise the type of HIV infection in the vast majority of the studies, which would improve the characterisation of the populations being studied, and the assessment of type-specific effects. Future research should also address the potential effect modification by sunlight exposure and provide RR estimates adjusted for the main confounders. The studies also involved analytical methods for the detection of HPV and/or HIV with different sensitivity and specificity. An example is the study by Simbiri et al (2010), where 31 out of 36 participants were HPV-positive using immunohistochemistry methods; however, HPV DNA was amplified with PCR in only 24 participants. Moreover, although in most studies the detection of HPV was based on viral DNA amplification by PCR, some searched for a large spectrum of mucosal subtypes, whereas others only aimed to detect specific subtypes.

The ORs computed for the studies that did not detect HPV infection among subjects of the control group represent inaccurate estimates of the true association between HPV infection and OSSN. Although the option for adding 0.5 to all cells of the contingency table yields OR estimates with very wide $95 \% \mathrm{CI}$, and therefore not expected to have a meaningful impact on the summary RR estimates, these results suggest a strong association between HPV infection and OSSN, and being able to consider them in the meta-analysis allows a much more efficient summary of the available evidence.

Human immunodeficiency virus was shown to be a strong risk factor for OSSN. A recent systematic review aiming at evaluating the effect of interventions for treating SCCC among HIV-infected patients showed that no randomised controlled trial had been conducted in HIV-positive patients, and the evidence on currently available treatments comes from analyses of case reports or cases series (Gichuhi and Irlam, 2013). Further research is needed on strategies to improve early diagnosis and treatment of OSSN among HIV-positive patients.

Although evidence-based treatments for OSSN are needed, prevention of its occurrence cannot be overemphasised. Ocular surface squamous neoplasias are not so rare conditions in many African settings (Chokunonga et al, 1999; Parkin et al, 1999) where access to highly active antiretroviral therapy is far from universal (Tanser et al, 2013). Improving the access to HAART, especially in settings with concomitant high prevalence of HPV infection, has the potential to substantially decrease the burden of OSSN (Holkar et al, 2005; Bekele et al, 2013). Moreover, the two prophylactic HPV vaccines commercialised in the last few years contain viruslike particles for four HPV mucosal subtypes (6, 11, 16 and 18), and much has been speculated on the impact of HPV vaccination in the prevention of eye disease (Hughes et al, 2008). Taking into account our results and the subtypes of HPV infection that can be prevented by the vaccine, the incidence of OSSN should not be expected to decrease because of vaccination.

In conclusion, HIV infection increases the risk of OSSN by eight-fold, whereas regarding the effects of HPV infection the available evidence suggests that only the cutaneous HPV subtypes are associated with an increased risk of OSSN.

\section{ACKNOWLEDGEMENTS}

We gratefully acknowledge the collaboration of Olga Laszczynska and Dr Xiao-Si Wang who helped in the screening of reference lists of the articles written in Polish and Chinese, respectively. The work of CC was supported by the Grant number R24TW008908 from the Fogarty International Center. This award is supported by funds provided to the NIH and HRSA under the 'Tom Lantos and Henry Hyde United States Leadership Against HIV/AIDS, Tuberculosis, and Malaria Reauthorization Act of 2008,' Public Law 110-293, which is more commonly known as the U.S. Presidents Emergency Plan for AIDS Relief (PEPFAR). Co-funding is also provided by the NIH Office of Research on Women's Health and the Office of AIDS Research. 


\section{DISCLAIMER}

The content is solely the responsibility of the authors and does not necessarily represent the official views of the Fogarty International Center or the National Institutes of Health.

\section{REFERENCES}

Adachi W, Nishida K, Shimizu A, Soma H, Yokoi N, Kinoshita S (1995) Human papilloma virus in the conjunctiva in ocular surface diseases. Jpn J Clin Ophthalmol 49(3): 439-442.

Asadi-Amoli F, Heidari AB, Jahanzad I, Jabbarvand M (2011) Detection of human papillomavirus in squamous cell carcinoma of conjunctiva by nested PCR: a case control study in Iran. Acta Med Iran 49(11): 707-714

Ateenyi-Agaba C (1995) Conjunctival squamous-cell carcinoma associated with HIV infection in Kampala, Uganda. Lancet 345(8951): 695-696.

Ateenyi-Agaba C, Franceschi S, Wabwire-Mangen F, Arslan A, Othieno E, Binta-Kahwa J, van Doorn LJ, Kleter B, Quint W, Weiderpass E (2010) Human papillomavirus infection and squamous cell carcinoma of the conjunctiva. Br J Cancer 102(2): 262-267.

Ateenyi-Agaba C, Weiderpass E, Smet A, Dong W, Dai M, Kahwa B, Wabinga H, Katongole-Mbidde E, Franceschi S, Tommasino M (2004) Epidermodysplasia verruciformis human papillomavirus types and carcinoma of the conjunctiva: a pilot study. Br J Cancer 90(9): 1777-1779.

Auw-Haedrich C, Martin G, Spelsberg H, Sundmacher R, Freudenberg N, Maier P, Reinhard T (2008) Expression of p16 in conjunctival intraepithelial neoplasia does not correlate with HPV-infection. Open Ophthalmol J 2: 48-56.

Bekele S, Gelaw Y, Tessema F (2013) Ocular manifestation of HIV/AIDS and correlation with CD4 + cells count among adult HIV/AIDS patients in Jimma town, Ethiopia: a cross sectional study. BMC Ophthalmol 13: 20.

Bouvard V, Baan R, Straif K, Grosse Y, Secretan B, El Ghissassi F, BenbrahimTallaa L, Guha N, Freeman C, Galichet L, Cogliano V (2009) A review of human carcinogens-Part B: biological agents. Lancet Oncol 10(4): 321-322.

Carrilho C, Gouveia P, Yokohama H, Lopes JM, Lunet N, Ferro J, Ismail M, Walboomers J, Sobrinho-Simoes M, David L (2013) Human

papillomaviruses in intraepithelial neoplasia and squamous cell carcinoma of the conjunctiva: a study from Mozambique. Eur J Cancer Prev; e-pub ahead of print 7 June 2013; doi: 10.1097/CEJ.0b013e328363005d.

Chauhan S, Sen S, Sharma A, Dar L, Kashyap S, Kumar P, Bajaj MS, Tandon R (2012) Human papillomavirus: a predictor of better survival in ocular surface squamous neoplasia patients. Br J Ophthalmol 96(12): 1517-1521.

Chinogurei TS, Masanganise R, Rusakaniko S, Sibanda E (2006) Ocular surface squamous neoplasia (OSSN) and human immunodeficiency virus at Sekuru Kaguvi Eye Unit in Zimbabwe: the role of operational research studies in a resource poor environment? Cent Afr J Med 52(5-6): 56-58.

Chokunonga E, Levy LM, Bassett MT, Borok MZ, Mauchaza BG, Chirenje MZ, Parkin DM (1999) Aids and cancer in Africa: the evolving epidemic in Zimbabwe. AIDS 13(18): 2583-2588.

de Koning MN, Waddell K, Magyezi J, Purdie K, Proby C, Harwood C, Lucas S, Downing R, Quint WG, Newton R (2008) Genital and cutaneous human papillomavirus (HPV) types in relation to conjunctival squamous cell neoplasia: a case-control study in Uganda. Infect Agent Cancer 3: 12.

de Villiers EM, Fauquet C, Broker TR, Bernard HU, zur Hausen H (2004) Classification of papillomaviruses. Virology 324(1): 17-27.

Di Girolamo N (2012) Association of human papilloma virus with pterygia and ocular-surface squamous neoplasia. Eye 26(2): 202-211.

Dushku N, Hatcher SL, Albert DM, Reid TW (1999) p53 expression and relation to human papillomavirus infection in pingueculae, pterygia, and limbal tumors. Arch Ophthalmol 117(12): 1593-1599.

Ebughe GA, Ekanem I, Omotoso AJ, Inyama M, Agan TU, Agan TU, Ago BU, Ibangha A, Nkangha D, Etiuma U, Inah G (2012) Malignancies in AIDS patients: the experience of a tertiary hospital in a high prevalence zone. Infect Agent Cancer 7(Suppl 1): 17.

Eng HL, Lin TM, Chen SY, Wu SM, Chen WJ (2002) Failure to detect human papillomavirus DNA in malignant epithelial neoplasms of conjunctiva by polymerase chain reaction. Am J Clin Pathol 117(3): 429-436.

Gichuhi S, Irlam JH (2013) Interventions for squamous cell carcinoma of the conjunctiva in HIV-infected individuals. Cochrane Database Syst Rev 2 CD005643.
Goedert JJ, Cote TR (1995) Conjunctival malignant disease with AIDS in USA. Lancet 346(8969): 257-258.

Grossniklaus HE, Green WR, Luckenbach M, Chan CC (1987) Conjunctival lesions in adults. A clinical and histopathologic review. Cornea 6(2): 78-116.

Grulich AE, van Leeuwen MT, Falster MO, Vajdic CM (2007) Incidence of cancers in people with HIV/AIDS compared with immunosuppressed transplant recipients: a meta-analysis. Lancet 370(9581): 59-67.

Guech-Ongey M, Engels EA, Goedert JJ, Biggar RJ, Mbulaiteye SM (2008) Elevated risk for squamous cell carcinoma of the conjunctiva among adults with AIDS in the United States. Int J Cancer 122(11): 2590-2593.

Guthoff R, Marx A, Stroebel P (2009) No evidence for a pathogenic role of human papillomavirus infection in ocular surface squamous neoplasia in Germany. Curr Eye Res 34(8): 666-671.

Harris RJ, Bradburn MJ, Deeks JJ, Harbord RM, Altman DG, Sterne JAC (2008) metan: fixed- and random-effects meta-analysis. Stata J 8(1): $3-28$.

Higgins JP, Thompson SG (2002) Quantifying heterogeneity in a meta-analysis. Stat Med 21(11): 1539-1558.

Holkar S, Mudhar HS, Jain A, Gupta M, Rogstad KE, Parsons MA, Singh AD, Rennie IG (2005) Regression of invasive conjunctival squamous carcinoma in an HIV-positive patient on antiretroviral therapy. Int J STD AIDS 16(12): 782-783.

Hughes DS, Powell N, Fiander AN (2008) Will vaccination against human papillomavirus prevent eye disease? A review of the evidence. $\mathrm{Br}$ J Ophthalmol 92(4): 460-465.

IARC Working Group on the Evaluation of Carcinogenic Risks to Humans (2012) IARC Monographs. A Review of Human Carcinogens. Biological Agents. v. 100B. World Health Organization, International Agency for Research on Cancer: Lyon, France.

Karcioglu ZA, Issa TM (1997) Human papilloma virus in neoplastic and non-neoplastic conditions of the external eye. Br J Ophthalmol 81(7): 595-598.

Kestelyn P, Stevens AM, Ndayambaje A, Hanssens M, van de Perre P (1990) HIV and conjunctival malignancies. Lancet 336(8706): 51-52.

Kiire CA, Dhillon B (2006) The aetiology and associations of conjunctival intraepithelial neoplasia. Br J Ophthalmol 90(1): 109-113.

Manderwad GP, Kannabiran C, Honavar SG, Vemuganti GK (2009) Lack of association of high-risk human papillomavirus in ocular surface squamous neoplasia in India. Arch Pathol Lab Med 133(8): 1246-1250.

Mbulaiteye SM, Katabira ET, Wabinga H, Parkin DM, Virgo P, Ochai R, Workneh M, Coutinho A, Engels EA (2006) Spectrum of cancers among HIV-infected persons in Africa: the Uganda AIDS-Cancer Registry Match Study. Int J Cancer 118(4): 985-990.

McDonnell JM, Mayr AJ, Martin WJ (1989) DNA of human papillomavirus type 16 in dysplastic and malignant lesions of the conjunctiva and cornea. N Engl J Med 320(22): 1442-1446.

McDonnell JM, McDonnell PJ, Mounts P, Wu TC, Green WR (1986) Demonstration of papillomavirus capsid antigen in human conjunctival neoplasia. Arch Ophthalmol 104(12): 1801-1805.

Moubayed P, Mwakyoma H, Schneider DT (2004) High frequency of human papillomavirus 6/11,16, and 18 infections in precancerous lesions and squamous cell carcinoma of the conjunctiva in subtropical Tanzania. Am J Clin Pathol 122(6): 938-943.

Nagaiah G, Stotler C, Orem J, Mwanda WO, Remick SC (2010) Ocular surface squamous neoplasia in patients with HIV infection in sub-Saharan Africa. Curr Opin Oncol 22(5): 437-442.

Newton R (1996) A review of the aetiology of squamous cell carcinoma of the conjunctiva. Br J Cancer 74(10): 1511-1513.

Newton R, Grulich A, Beral V, Sindikubwabo B, Ngilimana PJ, Nganyira A, Parkin DM (1995) Cancer and HIV infection in Rwanda. Lancet 345(8961): 1378-1379.

Newton R, Ziegler J, Ateenyi-Agaba C, Bousarghin L, Casabonne D, Beral V, Mbidde E, Carpenter L, Reeves G, Parkin DM, Wabinga H, Mbulaiteye S, Jaffe H, Bourboulia D, Boshoff C, Touze A, Coursaget P (2002) The epidemiology of conjunctival squamous cell carcinoma in Uganda. $\mathrm{Br}$ J Cancer 87(3): 301-308.

Palazzi MA, Erwenne CM, Villa LL (2000) Detection of human papillomavirus in epithelial lesions of the conjunctiva. Sao Paulo Med J 118(5): 125-130.

Parkin DM, Wabinga H, Nambooze S, Wabwire-Mangen F (1999) AIDS-related cancers in Africa: maturation of the epidemic in Uganda. AIDS 13(18): 2563-2570. 
Porges Y, Groisman GM (2003) Prevalence of HIV with conjunctival squamous cell neoplasia in an African provincial hospital. Cornea 22(1): 1-4.

Reid TW, Dushku N (2003) Does human papillomavirus cause pterygium? Br J Ophthalmol 87(7): 806-808.

Saegusa M, Takano Y, Hashimura M, Okayasu I, Shiga J (1995) HPV type 16 in conjunctival and junctional papilloma, dysplasia, and squamous cell carcinoma. J Clin Pathol 48(12): 1106-1110.

Sasco AJ, Jaquet A, Boidin E, Ekouevi DK, Thouillot F, Lemabec T, Forstin MA, Renaudier P, N'Dom P, Malvy D, Dabis F (2010) The challenge of AIDS-related malignancies in sub-Saharan Africa. PLoS One 5(1): e8621.

Scott IU, Karp CL, Nuovo GJ (2002) Human papillomavirus 16 and 18 expression in conjunctival intraepithelial neoplasia. Ophthalmology 109(3): 542-547.

Sen S, Sharma A, Panda A (2007) Immunohistochemical localization of human papilloma virus in conjunctival neoplasias: a retrospective study. Indian J Ophthalmol 55(5): 361-363.

Shields CL, Ramasubramanian A, Mellen PL, Shields JA (2011) Conjunctival squamous cell carcinoma arising in immunosuppressed patients (organ transplant, human immunodeficiency virus infection). Ophthalmology 118(11): 2133-2137 el.

Simbiri KO, Murakami M, Feldman M, Steenhoff AP, Nkomazana O, Bisson G, Robertson ES (2010) Multiple oncogenic viruses identified in Ocular surface squamous neoplasia in HIV-1 patients. Infect Agent Cancer 5: 6.

Sptizer MS, Chirambo T, Kayange P, Szurman P, Yoeruek E, Bartz-Schmidt KU, Batumba HN (2009) The influence of the HIV pandemic on the incidence of malignant ocular tumours in Southern Malawi (Blantyre). Ophthalmaloge 106(9): 813-818.

Sterne JA, Gavaghan D, Egger M (2000) Publication and related bias in meta-analysis: power of statistical tests and prevalence in the literature. J Clin Epidemiol 53(11): 1119-1129.
Tabrizi SN, McCurrach FE, Drewe RH, Borg AJ, Garland SM, Taylor HR (1997) Human papillomavirus in corneal and conjunctival carcinoma. Aust N Z J Ophthalmol 25(3): 211-215.

Tanser F, Barnighausen T, Grapsa E, Zaidi J, Newell ML (2013) High coverage of ART associated with decline in risk of HIV acquisition in rural KwaZulu-Natal, South Africa. Science 339(6122): 966-971.

Timm A, Stropahl G, Schittkowski M, Sinzidi C, Kayembe D, Guthoff R (2004) Association of malignant tumors of the conjunctiva and HIV infection in Kinshasa (D. R. Congo). First results. Ophthalmologe 101(10): 1011-1016.

Tornesello ML, Duraturo ML, Waddell KM, Biryahwaho B, Downing R, Balinandi S, Lucas SB, Buonaguro L, Buonaguro FM (2006) Evaluating the role of human papillomaviruses in conjunctival neoplasia. $\mathrm{Br} J$ Cancer 94(3): 446-449.

Tulvatana W, Bhattarakosol P, Sansopha L, Sipiyarak W, Kowitdamrong E, Paisuntornsug T, Karnsawai S (2003) Risk factors for conjunctival squamous cell neoplasia: a matched case-control study. $\mathrm{Br}$ J Ophthalmol 87(4): 396-398.

Wabinga HR, Parkin DM, Wabwire-Mangen F, Nambooze S (2000) Trends in cancer incidence in Kyadondo County, Uganda, 1960-1997. Br J Cancer 82(9): 1585-1592.

Waddell K, Kwehangana J, Johnston WT, Lucas S, Newton R (2010) A case-control study of ocular surface squamous neoplasia (OSSN) in Uganda. Int J Cancer 127(2): 427-432.

Waddell KM, Lewallen S, Lucas SB, Atenyi-Agaba C, Herrington CS, Liomba G (1996) Carcinoma of the conjunctiva and HIV infection in Uganda and Malawi. Br J Ophthalmol 80(6): 503-508.

This work is published under the standard license to publish agreement. After 12 months the work will become freely available and the license terms will switch to a Creative Commons AttributionNonCommercial-Share Alike 3.0 Unported License.

Supplementary Information accompanies this paper on British Journal of Cancer website (http://www.nature.com/bjc) 